\title{
A Simulation on the Regeneration of Activated Carbon with an Indirect Heating Method
}

DOI: $10.15255 /$ KUI.2016.021 KUI-31/2016

Original scientific paper Received May 4, 2016 Accepted August 2, 2016

\author{
S. Yu, ${ }^{\mathrm{a}^{*}}$ J. Peng, ${ }^{\mathrm{b}^{* *}}$ X. Zhang, ${ }^{\mathrm{a}}$ and G. Wang ${ }^{\mathrm{b}}$ \\ a College of Chemical Engineering, Weifang Vocational College, Weifang \\ 261041 , P.R. China \\ ${ }^{b}$ Key Laboratory of Marine Chemistry Theory and Technology, Ministry of \\ Education, Ocean University of China, Qingdao 266 100, P.R. China
}

\begin{abstract}
\| Abstract
It is of great challenge and significance to recycle activated carbon (AC), yet still with various problems in operation. Here, we have performed a simulation on the regeneration of AC by using an indirect heating method with an unsteady cylindrical heat transfer model. The result has shown that the optimal parameters for a regeneration tube of outer diameter $\Phi=108$ with wall thickness $4 \mathrm{~mm}$ were: heating in the tube for $30 \mathrm{~min}$ at a surrounding temperature of $550{ }^{\circ} \mathrm{C}$. In these conditions, a temperature of $417.5^{\circ} \mathrm{C}$ could be obtained at the centre of the cylindrical tube, reaching the temperature required for AC regeneration. The experimental values obtained in our laboratory were consistent with the simulation, providing significant references for scaling up pilot plant of $\mathrm{AC}$ regeneration.
\end{abstract}

$\|$ Keywords

Activated carbon, regeneration, indirect heating, unsteady heat transfer

\section{Introduction}

With the improvement of regulations for environmental protection and the increasing expenditures for pollution control, China will be in the lead in application of activated carbon (AC). Highly porous carbonaceous materials are referred to as activated carbons that are applied in various fields owing to extraordinary characteristics. ${ }^{1,2}$ The features of these materials are large surface area, microporous and mesoporous structures, and versatile adsorption capacity for different heavy metal ions. Thereby, they can be applied as ideal adsorbents in many types of water purification systems. Because the pore dimensions of ACs are more or less close to the size of the adsorbate molecules, they exhibit high adsorption capacity. ${ }^{2-4}$ AC has become a suitable adsorbent for wastewater treatment in the last decades.

It is wasteful to use disposable AC due to its high pricing. Therefore, it is of great challenge and significance to restore the adsorption performance of $\mathrm{AC}$ by removing the adsorbates in its micropores with physical or chemical methods. Various approaches have been proposed to regenerate $\mathrm{AC},{ }^{5}$ such as heating at elevated temperatures, ${ }^{6}$ electric heating, ${ }^{7}$ wet oxidation, ${ }^{8}$ solvent regeneration, ${ }^{9}$ forced discharging, ${ }^{10}$ microwave regeneration, ${ }^{11}$ etc. However, only the first one could meet the needs of large-scale production. To date, high temperature heating usually depends on the conductivity of $\mathrm{AC}$ or direct heating by hot blast heater for regeneration. The former has disadvantages, such as low conductivity of AC, difficulty in controlling the operating conditions, high power consumption, etc.,

\footnotetext{
${ }^{*}$ Corresponding author 1: Shulan Yu e-mail: shulanyu05366668@163.com

${ }^{* *}$ Corresponding author 2: Jialin Peng e-mail: 1540124605@qq.com
}

whereas the latter process has an intrinsic disadvantage that oxygen in hot blast can easily lead to ashing of $A C$ or even high ablation rate caused by spontaneous combustion.

Schlunder" proposed the concept of "convective heat transfer of particles" to describe the heat transfer process with particles. The heat conduction between contact surfaces will dominate while the particle size is small, which is analogous to the heat transfer between continuous fluids. This conception can apply to the heat transfer process of AC particles. And a variety of models as well as related equations have been proposed.

Natarajan and Hunt ${ }^{13}$ studied the effect of shearing on the convective heat transferring from a heater immersed in a vertical granular flow in a channel. This model investigated the effect of particles microstructure on the heat transfer process. However, the calculation was redundant and difficult for engineering design.

Molerus ${ }^{14}$ investigated the contact resistance for the heat transferring between adjacent rough particles in moving bed, and elicited a model for qualitatively accounting for the short time heat transfer, as well as steady-state heat conduction in particle beds. However, relatively large errors were usually observed for unsteady state heat transfer.

Nozad et al. ${ }^{15,16}$ studied the heat transfer process with particles by effective medium approach (EMA). Specifically, according to the assumption of effective medium, the macro properties of the system as well as its transfer process would be connected with the microstructure and micro transfer features of the system, via replacing particles system by an isotropically homogeneous, effective medium. To obtain the distribution of the mean temperature of the particle flow, statistical averaging, and empirical correlation 
were applied to simplify the microstructure (composition, voidage, and texture) of the materials. This approach could be a useful reference to study the unsteady heat transfer of regenerative feed heating systems, because it is easy to use and convenient for engineering design.

Our preliminary experiments proved that indirect heating was better than direct heating in retaining the performance of AC. For example, we could retain $97 \%$ or higher strength of $\mathrm{AC}, 95 \%$ or higher recovery of adsorption capacity, and $0.5 \%$ or less ashing rate for more than ten cycles with indirect heating on AC. On the contrary, the ashing rate was higher than $2 \%$ when using direct heating, which had adverse effects on further use of AC. However, regeneration with indirect heating is a process of heating and heat transfer between solid interfaces, and a process of unsteady heat transfer. In this paper, we used EMA and nomographic method to simulate the indirect heating process. The result was consistent with the experimental values previously obtained in our laboratory, indicating that the method could provide meaningful references for related industries.

\section{Experimental}

As shown in Fig. 1, the heating furnace for AC regeneration is composed of a heating and a cooling chamber, a metallic regeneration tube, a stock feeding and discharging device.

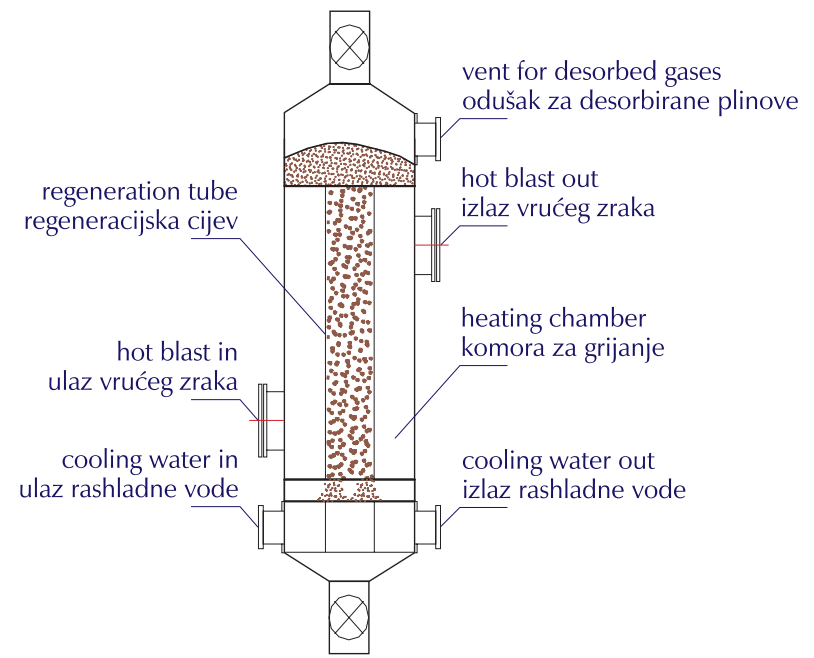

Fig. 1 - Heating furnace for AC regeneration

Slika 1 - Toplinska peć za regeneraciju AC-a

The saturated AC was fed and moved slowly top-down in the metallic regeneration tube. The tube with $\mathrm{AC}$ was heated to a temperature higher than $400{ }^{\circ} \mathrm{C}$ in the heating chamber. Harmful gases were desorbed from AC surface and sucked for recycling under negative pressure. The AC was then re-activated after desorption and returned to use after cooling and discharging.

\section{Results and discussion}

The major calculation methods for unsteady state heat transfer were analytical, ${ }^{17}$ lumped parameterizing and nomographic method, ${ }^{18}$ etc. The former two methods not only require the eigenvalue traced by Biot number, but also involve redundant calculation using Bessel function, and so on, which are inconvenient for engineering design. The nomographic method is easy to use for engineers, owing to its simplified calculation process. Therefore, in this study, we applied the nomographic method to the design and calculation of the regeneration of AC. The basic methodology and procedure are described below.

\subsection{Process of heat regeneration of $A C$ can be simplified as an unsteady heat transfer model of a cylinder}

To ensure the complete regeneration of $\mathrm{AC}$ and still avoid excessive loss from overtemperature, the temperature of the regeneration tube should be maintained at around $550{ }^{\circ} \mathrm{C} .{ }^{5,19}$ The $\mathrm{AC}$ gradually absorbs the heat from the surroundings when moving down in the regeneration tube, increasing its temperature to reach that required for regeneration. Since AC is a poor thermal conductor and the heating source of regeneration is from the outside combustor, the radial heat transfer was mainly considered while ignoring the axial transfer in the calculation. We can use the effective medium approach (EMA) for convenient calculation, and choose an AC column (AC cylinder) with a unit length as the objective. Then the heat absorbing process for regeneration of $\mathrm{AC}$ could be simplified as a problem of unsteady heat transfer of the AC cylinder at a constant temperature, by the assumption that $\mathrm{AC}$ is isotropically homogeneous.

\subsection{Biot number and the Fourier number}

The Biot number $(B i)$ and the Fourier number $\left(F_{O}\right)$ are required for the calculation of unsteady heat transfer of a cylinder with a graphical method. Bi and Fo are estimated using Eqs. (1)-(2):

$$
\begin{gathered}
B i=\frac{h \delta}{\lambda_{\mathrm{AC}}} \\
\text { FO }=\frac{\alpha t_{\text {heating }}}{\delta^{2}}
\end{gathered}
$$

where $h$ is the heat transfer coefficient between AC and the surroundings, which is assumed to be $50 \mathrm{Wm}^{-2} \mathrm{~K}^{-1}$ according to our preliminary experiments in the laborato$r y, \lambda_{\mathrm{AC}}$ is the thermal conductivity ${ }^{20}$ and is assumed to be $0.25 \mathrm{~W} \mathrm{~m}^{-1} \mathrm{~K}^{-1}$ in this study; $\delta$ is the design size, whose value is half of the thickness and the radius for an infinite plate and a cylinder, respectively. In this study, the regeneration tube is a seamless steel pipe of $\phi=108 \mathrm{~mm}$ with wall thickness $4 \mathrm{~mm}$, and thus the inner radius of the tube $(\delta)$ is $0.05 \mathrm{~m}$, as calculated in Eq. (3):

$$
\delta=\frac{108 \mathrm{~mm}-2 \cdot 4 \mathrm{~mm}}{2}=50 \mathrm{~mm}=0.05 \mathrm{~m}
$$


In Eq. (2), $t_{\text {heating }}$ is the heating time, which is usually set to an initial value of $1200 \mathrm{~s}$, and $\alpha$ is the thermal diffusivity, as calculated in Eq. (4):

$$
\alpha=\frac{\lambda_{\mathrm{AC}}}{\rho_{\mathrm{AC}} C_{\mathrm{AC}}}
$$

where $\rho_{\mathrm{AC}}$ is the bulk density of AC, ranging from 300 to $650 \mathrm{~kg} \mathrm{~m}^{-3}$ and a value of $500 \mathrm{~kg} \mathrm{~m}^{-3}$ was applied in this study, and $C_{A C}$ is the specific heat capacity of AC and was taken as $840 \mathrm{~J} \mathrm{~kg}^{-1} \mathrm{~K}^{-1}$ in this study. As a result, $\alpha$ was calculated to be $4.67 \cdot 10^{-7} \mathrm{~m}^{2} \mathrm{~s}^{-1}$ according to Eq. (4).

Consequently, based on Eqs. (1) to (4), Bi and Fo were calculated to be 12.5 and 0.2286 , respectively. Then $1 / B i$ is equal to 0.08 .

\subsection{Temperature at the centre of AC cylinder}

The temperature at the centre of AC cylinder can then be found from nomographic charts of temperature based on the Biot number and the Fourier number. Figs. 2 and 3 are the dimensionless nomographic charts of temperature at the centre of a cylinder during the process of unsteady heat transfer, which are usually called normalized graphs. Based on Fo and $1 / B i$, the ratio of $\theta_{\mathrm{m}} / \theta_{0}$ (the dimensionless central temperature) can then be found to be 0.35 (Fig. 2), where $\theta_{\mathrm{m}}$ is the temperature at the centre of AC layer, and $\theta_{0}$ the difference between the initial temperature of $A C$ layer $\left(\theta_{\text {ini }}\right)$ and the surrounding temperature $\left(\theta_{\mathrm{e}}\right)$. This temperature difference is $530{ }^{\circ} \mathrm{C}$ for $\theta_{\text {ini }}=20^{\circ} \mathrm{C}$, and $\theta_{\mathrm{e}}=550{ }^{\circ} \mathrm{C}$.
After that, the ratio of $\theta / \theta_{\mathrm{m}}$ can be found from Fig. 3 based on $1 / B i$ and $r / R$, where $\theta$ is the temperature at any point of the AC cylinder, $r$ and $R$ are the radial distances from that point to the central shaft and the radius of the cylinder, respectively.

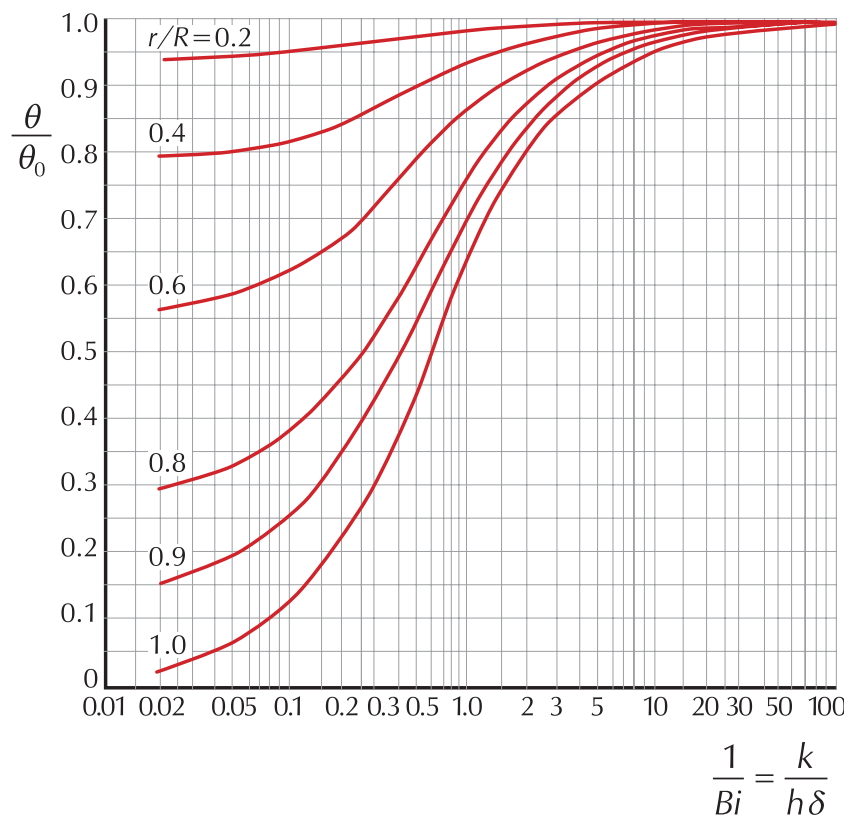

Fig. 3 - Nomographic chart of temperature at any point of the cylinder

Slika 3 - Nomogram temperature u bilo kojoj točki cilindra

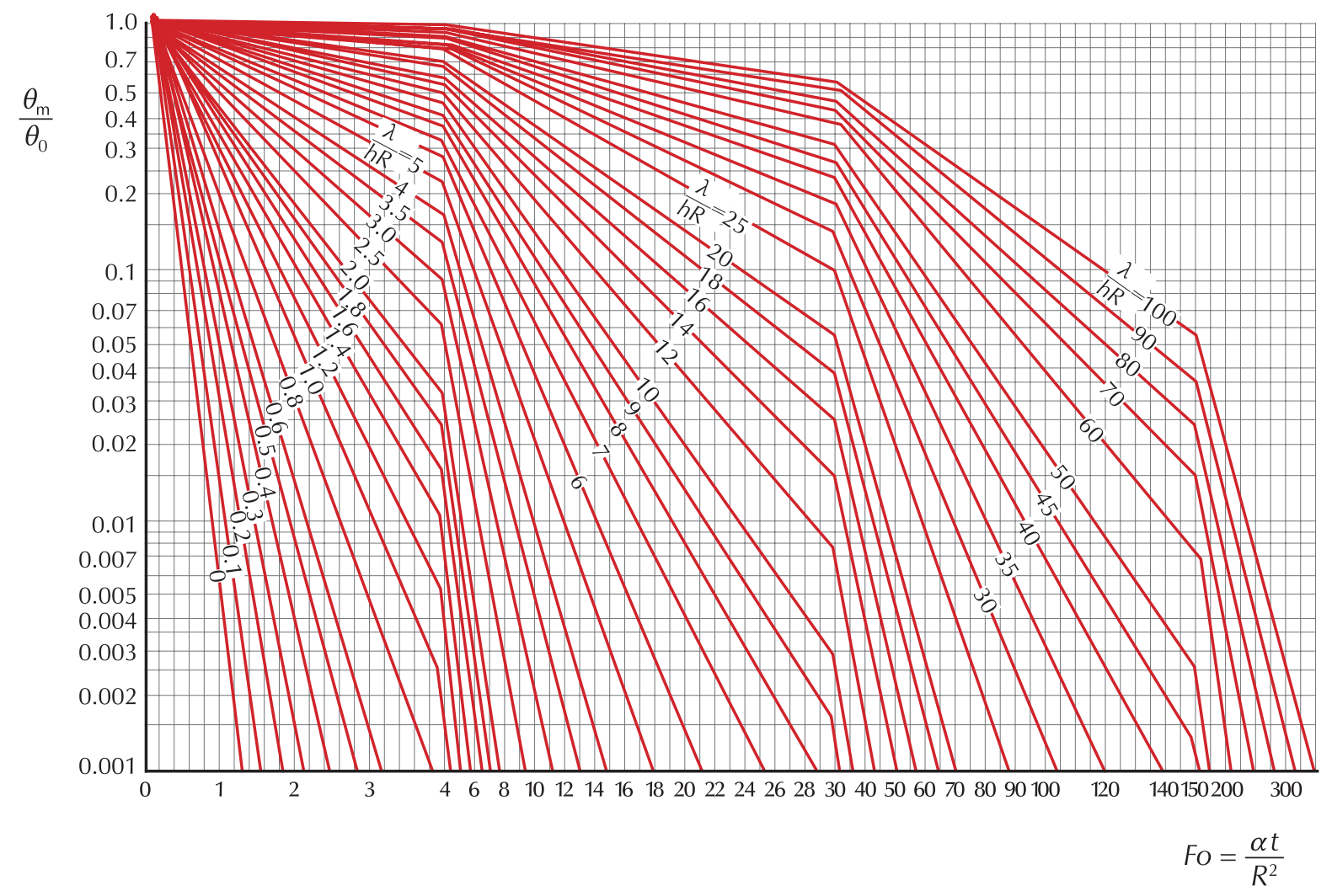

Fig. 2 - Nomographic chart of temperature at the centre of the cylinder Slika 2 - Nomogram temperature u središtu cilindra 
Since the heat transfer for $\mathrm{AC}$ regeneration is from the outside in, the lowest temperature is certainly found at the central part of the AC cylinder. As long as the central temperature reaches that for $\mathrm{AC}$ regeneration, the temperature of the whole AC cylinder could definitely meet the requirements. On the other hand, the ratio of $r / R$ is zero at the centre of the $\mathrm{AC}$ cylinder; the corresponding ratio of $\theta / \theta_{\mathrm{m}}$ is then equal to 1.0 regardless of the value of $1 / \mathrm{Bi}$ (Fig. 3). Thus, the ratio of $\theta / \theta_{0}$ was then obtained from Eq. (5):

$$
\frac{\theta}{\theta_{0}}=\left(\frac{\theta}{\theta_{\mathrm{m}}}\right) \cdot\left(\frac{\theta_{\mathrm{m}}}{\theta_{0}}\right)=1 \times 0.35=0.35
$$

The core temperature $\left(\theta_{\text {centre }}\right)$ can then be deduced from Eq. (6):

$\theta_{\text {centre }}=\left(\frac{\theta}{\theta_{0}}\right) \cdot \theta_{0}+\theta_{\mathrm{e}}=0.35 \times(-530)+550=364.5^{\circ} \mathrm{C}$

That is to say, for AC in a regeneration tube of $\phi=108 \mathrm{~mm}$ with wall thickness $4 \mathrm{~mm}$ with an initial temperature of $20{ }^{\circ} \mathrm{C}$ and a surrounding temperature of $550{ }^{\circ} \mathrm{C}$, the core temperature can only reach $364.5^{\circ} \mathrm{C}$ within 20 min, which is insufficient for $\mathrm{AC}$ regeneration $\left(400^{\circ} \mathrm{C}\right)$.

Therefore, a re-calculation should be performed with the heating time reset. For a reset heating time of $1800 \mathrm{~s}$, a similar procedure as above resulted in a Fo value of 0.3428 . Based on Fig. 2, the ratio of $\theta_{\mathrm{m}} / \theta_{0}$ can then be found to be 0.25 . The ratio of $\theta / \theta_{0}$ was the same (i.e. 0.25 ) according to Fig. 3. That yields a core temperature $\left(\theta_{\text {centre }}\right)$ of $417.5^{\circ} \mathrm{C}$, which is sufficiently high for AC regeneration. In summary, under a surrounding temperature of $550{ }^{\circ} \mathrm{C}, \mathrm{AC}$ in a regeneration tube of $\Phi=108 \mathrm{~mm}$ with wall thickness $4 \mathrm{~mm}$ should stay for at least 30 minutes to allow the core temperature to reach that required for regeneration.

We also selected a regeneration tube of $\phi=168 \mathrm{~mm}$ with wall thickness $6 \mathrm{~mm}$ for comparison. For a heating time of
$30 \mathrm{~min}$, the finally obtained value of $\theta_{\text {centre }}$ was $126^{\circ} \mathrm{C}$. It is obvious that the core temperature would only be $126{ }^{\circ} \mathrm{C}$ in a heating time of 30 minutes if an oversized regeneration tube is selected, far less than $400{ }^{\circ} \mathrm{C}$. These results suggested that the heating time for $\mathrm{AC}$ in a tube to reach the temperature required for regeneration increases with increasing the diameter of the tube, which is unfavourable for large-scale industrial operation. This is attributed to the fact that $A C$ is a poor thermal conductor; and a longer time is required for heat transfer to the centre of the tube with increasing the diameter. However, an undersized one could easily cause blocking because of the "bridging" effect between AC particles in the tube. As a result, we recommend a regeneration tube with a diameter of around $\Phi=100 \mathrm{~mm}$.

\subsection{Calculation of heat transfer}

The heat transferred to the AC cylinder can also be obtained from nomographic chart of heat based on the Biot number and the Fourier number. The dimensionless nomographic chart of heat for a cylinder during the process of unsteady heat transfer is shown in Fig. 4, where $Q$ refers to the heat absorbed per length of AC column during a period of $30 \mathrm{~min}$, and $Q_{0}$ refers to the heat absorbed per length of $\mathrm{AC}$ column for its temperature increasing from the initial temperature $\theta_{\text {ini }}$ to the surrounding temperature $\theta_{e} ; q$ is the heat absorbed per mass of AC during the time of 30 minutes.

First, the value of $\mathrm{FOBi}^{2}$ was calculated.

$$
F_{O B i^{2}}=0.3428 \times 12.52=53.57
$$

And then, based on $F O B i^{2}$ and $B i$, the value of $Q / Q_{0}$ can be found to be 0.75 from Fig. 4. $Q_{0}$ is calculated according to Eq. (7):

$$
Q_{0}=\pi R^{2} \rho_{\mathrm{AC}} C_{\mathrm{AC}}\left(\theta_{\mathrm{e}}-\theta_{\mathrm{ini}}\right)=1748300.4 \mathrm{~J} \mathrm{~m}^{-1}
$$

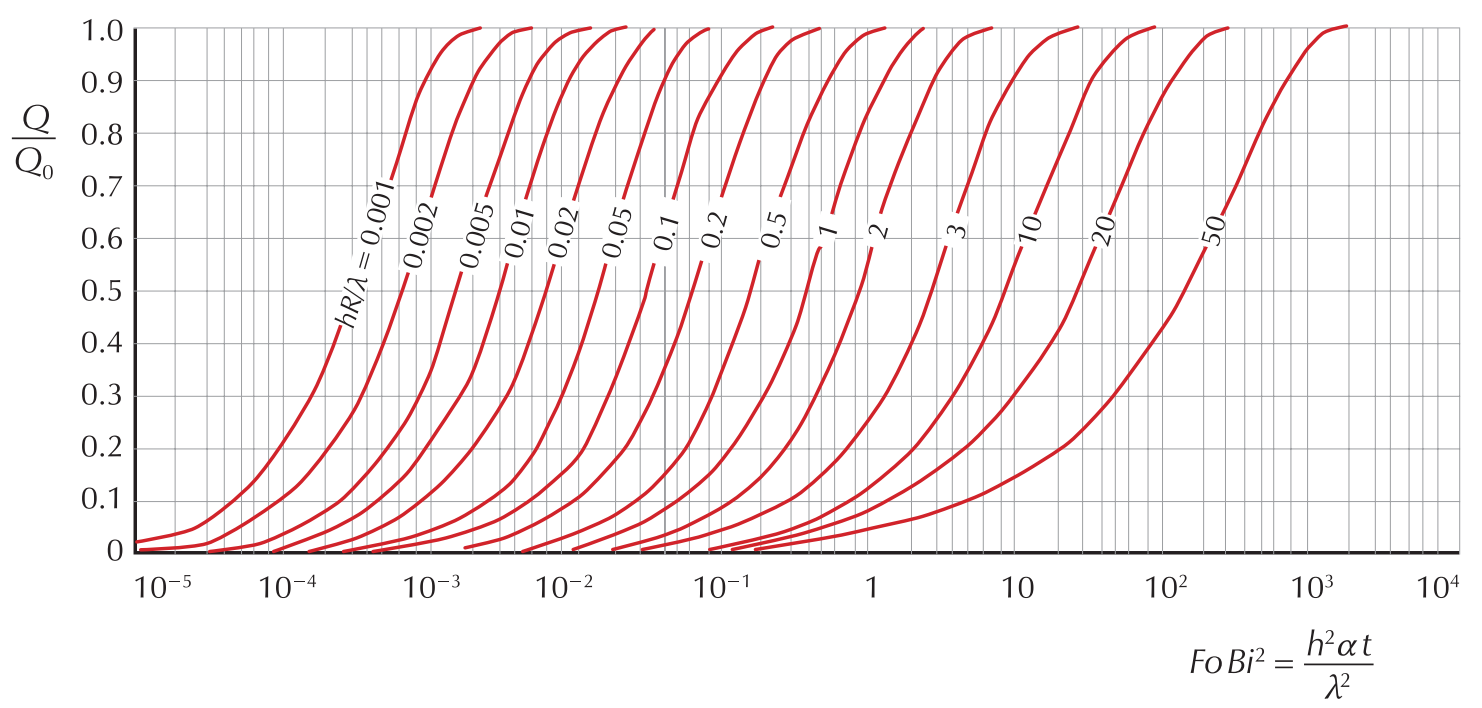

Fig. 4 - Nomographic chart of heat for a cylinder during the process of unsteady heat transfer Slika 4 - Nomogram topline cilindra tijekom procesa nestacionarnog prijenosa topline 
$Q$ and $q$ are estimated by using Eqs. (8) and (9).

$$
\begin{aligned}
Q & =\left(\frac{Q}{Q_{0}}\right) Q_{0}= \\
& =0.75 \times 1748300.4 \mathrm{~J} \mathrm{~m}^{-1}=1311225.3 \mathrm{~J} \mathrm{~m}^{-1} \\
q & =\frac{Q}{\rho_{\mathrm{AC}} \pi R^{2}}=\frac{1311225.3}{500 \times 3.14 \times 0.05^{2}} \mathrm{~J} \mathrm{~kg}^{-1}=333.9 \mathrm{~kJ} \mathrm{~kg}^{-1}
\end{aligned}
$$

The experimental testing of $\mathrm{AC}$ regeneration conducted in our laboratory showed that, under a surrounding temperature of $550{ }^{\circ} \mathrm{C}$, the core temperature of $\mathrm{AC}$ in the regeneration tube was about $422{ }^{\circ} \mathrm{C}$ during a heating time of 30 minutes, which is in very good agreement with the calculation.

\section{Conclusion}

The heat absorbing process for regeneration of AC could be simplified as a problem of unsteady heat transfer of the AC cylinder at a constant temperature. Based on the EMA of particle heat transfer model, we analysed the indirect heating reactivation process of $\mathrm{AC}$ particles and then we made the calculation of regeneration tube.

The diameter of $\mathrm{AC}$ regeneration tube is critical to the regeneration by using a heating furnace. The heating time for $\mathrm{AC}$ in a tube to reach the temperature required for regeneration increases with increasing the diameter of the tube, which is unfavourable for large-scale industrial operation. However, an undersized tube could easily cause blocking because of the "bridging" effect between AC particles. According to our calculation and experimental testing, a regeneration tube with a diameter of around $\phi=100 \mathrm{~mm}$ was recommended. With a regeneration tube of this size and a surrounding temperature of $550{ }^{\circ} \mathrm{C}$, the core temperature of $\mathrm{AC}$ could reach $400{ }^{\circ} \mathrm{C}$ or higher during a heating time of 30 minutes in the tube, which is sufficient for AC regeneration. The results of this study could provide meaningful references for related industries of $A C$ regeneration.

\section{List of symbols and abbreviations Popis simbola i kratica}

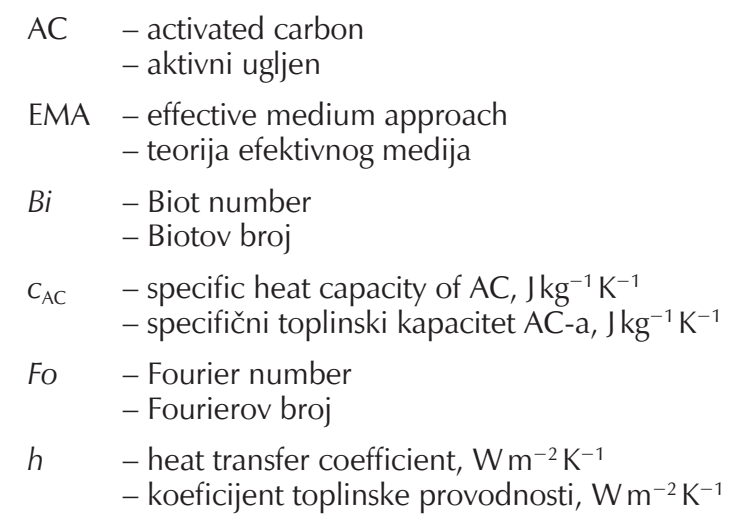

Q - heat absorbed per length of AC column during a period of 30 minutes, $\mathrm{J}$

- dovedena toplina po duljini stupca AC-a tijekom 30 minuta, J

$Q_{0} \quad$ - heat absorbed per length of AC column for temperature increase $\theta_{\mathrm{e}}-\theta_{\text {ini, }}$ J

- dovedena toplina po duljini stupca AC-a za porast temperature $\theta_{\mathrm{e}}-\theta_{\text {ini, }}$ J

$q$ - heat absorbed per mass of AC during the time of 30 minutes, J

- dovedena toplina po masi AC-a tijekom 30 minuta, J

$R \quad$ - radius of the cylinder

- polumjer cilindra

$r \quad$ - radial distance from the central shaft

- udaljenost od osi cilindra

$t_{\text {heating }}-$ heating time, $s$

- vrijeme zagrijavanja, $s$

$\alpha \quad-$ thermal diffusivity, $\mathrm{m}^{2} \mathrm{~s}^{-1}$

- toplinska difuzivnost, $\mathrm{m}^{2} \mathrm{~s}^{-1}$

$\delta$ - characteristic dimension, inner radius of the tube, $\mathrm{m}$, $\mathrm{mm}$

- karakteristična dimenzija, unutarnji polumjer cijevi, m, $\mathrm{mm}$

$\theta_{0} \quad$ difference between the initial temperature of AC layer $\left(\theta_{\text {ini }}\right)$ and the surrounding temperature $\left(\theta_{\mathrm{e}}\right),{ }^{\circ} \mathrm{C}$

razlika između početne temperature $\mathrm{AC}-\mathrm{a}\left(\theta_{\text {ini }}\right)$ i okolne temperature $\left(\theta_{\mathrm{e}}\right),{ }^{\circ} \mathrm{C}$

$\theta_{\text {centre }}$ - core temperature, ${ }^{\circ} \mathrm{C}$

- temperatura jezgre, ${ }^{\circ} \mathrm{C}$

$\theta_{\mathrm{e}} \quad$ - surrounding temperature, ${ }^{\circ} \mathrm{C}$

- okolna temperatura, ${ }^{\circ} \mathrm{C}$

$\theta_{\text {ini }} \quad$ - initial temperature of $\mathrm{AC}$ layer, ${ }^{\circ} \mathrm{C}$

- početna temperatura sloja AC-a, ${ }^{\circ} \mathrm{C}$

$\theta_{\mathrm{m}} \quad$ - the temperature at the centre of $\mathrm{AC}$ layer, ${ }^{\circ} \mathrm{C}$

- temperatura u središtu sloja $\mathrm{AC}-\mathrm{a},{ }^{\circ} \mathrm{C}$

$\lambda_{\mathrm{AC}} \quad$ - thermal conductivity, $\mathrm{W} \mathrm{m}^{-1} \mathrm{~K}^{-1}$

- toplinska provodnost, $\mathrm{W} \mathrm{m}^{-1} \mathrm{~K}^{-1}$

$\rho_{\mathrm{AC}} \quad-$ bulk density of $\mathrm{AC}, \mathrm{kg} \mathrm{m}^{-3}$

- nasipna gustoća AC-a, $\mathrm{kg} \mathrm{m}^{-3}$

$\Phi \quad$ - outer diameter of the tube, $\mathrm{mm}$

- vanjski promjer cijevi, mm

\section{References \\ Literatura}

1. A. Ahmadpour, N. Eftekhari, A. Ayati, Performance of MWCNTs and a low-cost adsorbent for Chromium(VI) ion removal, J. Nanostruct. Chem. 4 (4) (2014) 171-178, doi: http://dx.doi.org/10.1007/s40097-014-0119-9.

2. S, Parlayici, V. Eskizeybek, A. Avcı, E. Pehlivan, Removal of chromium (VI) using activated carbon-supported functionalized carbon nanotubes, J. Nanostruct. Chem. 5 (2015) 255263, doi: http://dx.doi.org/10.1007/s40097-015-0156-z.

3. S. J. Allen, L. Whitten, G. Mckay, The production and characterization of activated carbons: a review, Dev. Chem. Eng. Min. 6 (1998) 231-261.

4. R. T. Yang, Adsorbents: Fundamentals and Applications, John Wiley \& Sons, Hoboken, 2003.

5. Y. Wu, Regeneration methods of activated carbon, Chem. 
Production Technol. 12 (1) (2005) 20-23, doi: http://dx.doi. org/10.1002/jctb.1142.

6. Y. I. Matatovmeytal, M. Sheintuch, G. E. Shter, G. S. Grader, Optimal temperatures for catalytic regeneration of activated carbon, Carbon 35 (10) (1997) 1527-1531, doi: http://dx. doi.org/10.1016/S0008-6223(97)00103-6.

7. P. D. Sullivan, M. J. Rood, G. Grevillot, J. D. Wander, K. J. Hay, Activated carbon fiber cloth electrothermal swing adsorption system, Environ. Sci. Technol. 38 (18) (2004) 4865-4877, doi: http://dx.doi.org/10.1021/es0306415.

8. Z. H. Yue, Study on Activated Carbon Regeneration by High Voltage Pulse Discharge. M. Sc. Thesis, China University of Petroleum, 2010.

9. D. O. Cooney, A. Nagerl, A. L. Hines, Solvent regeneration of activated carbon, Water Res. 17 (4) (1983) 403-410, doi: http://dx.doi.org/10.1016/0043-1354(83)90136-7.

10. P. Li, F. L. Wang, P. Yuan, Mechanism and Application of Activated Carbon Regeneration Furnace by Forced-discharge, Jiangsu Environ. Sci. Technol. 21 (2) (2008) 1-3.

11. L. Q. Zhang, H. T. Jiang, D. Yong, Microwave regeneration characteristics of activated carbon for flue gas desulfurization, J. Fuel Chem. Technol. 40 (11) (2012) 1366-1371, doi: http://dx.doi.org/10.1016/S1872-5813(13)60004-3.

12. E. U. Schlunder, Particle heat transfer, Heat Transfer 1 (1982) 195-211.

13. V. V. R. Natarajan, M. L. Hunt, Heat transfer in vertical granular flows, Int. J. Heat Mass Transfer 10 (2) (1997) 89-107, doi: http://dx.doi.org/10.1080/08916159708946536.

14. O. Molerus, Heat transfer in moving beds with a stagnant interstitial gas, Int. J. Heat Mass Transfer 40 (17) (1997) 4151-4159, doi: http://dx.doi.org/10.1016/S0017-9310(97)00030-6.

15. I. Nozad, R. G. Carbonell, S. Whitaker, Heat conduction in multiphase systems - I: theory and experiment for twophase systems, Chem. Eng. Sci. 40 (5) (1985) 843-855, doi: http://dx.doi.org/10.1016/0009-2509(85)85038-7.

16. I. Nozad, R. G. Carbonell, S. Whitaker, Heat conduction in multiphase systems - II: Experimental method and results for three-phase systems, Chem. Eng. Sci. 40 (5) (1985) 857-863, doi: http://dx.doi.org/10.1016/0009-2509(85)85038-7.

17. M. Ya. Brovman, Application of isothermal surfaces for calculation of unsteady heat transfer processes, J. Eng. Phys. Thermophys. 71 (5) (1998) 917-923, doi: http://dx.doi. org/10.1007/BF02681646.

18. A. M. Vorob'ev, V. I. Zhuk, V. P. Sizov, D. N. Chubarov, Analysis of nonsteady thermal model of a thin membrane sensor of heat-flux density, J. Eng. Phys. 58 (2) (1990) 203-208, doi: http://dx.doi.org/10.1007/BF00872849.

19. G. Zhang, J. Qu, H. Liu, A. T. Cooper, R. Wu, CuFe $\mathrm{O}_{4} / \mathrm{ac}-$ tivated carbon composite: A novel magnetic adsorbent for the removal of acid orange II and catalytic regeneration, Chemosphere 68 (2007) 1058-1066, doi: http://dx.doi. org/10.1016/j.chemosphere.2007.01.081.

20. Z. J. Su, N. T. Pan, W. Zhao, J. L. Mo, H. X. Xi, Preparation and properties of activated carbons with high thermal conductivity, Chem. Eng. (China) 40 (12) (2012) 14-18.

\section{SAŽETAK}

\section{Simulacija regeneracije aktivnog ugljena neizravnim grijanjem Shulan Yu, ${ }^{a^{*}}$ Jialin Peng, ${ }^{\mathrm{b}^{* *}}$ Xinwen Zhang ${ }^{\mathrm{a}} \mathrm{i}$ Guoguang Wang ${ }^{\mathrm{b}}$}

Recikliranje aktivnog ugljena (AC) iznimno je važno i interesantno, no još se uvijek javljaju različiti problemi u provedbi postupka. $U$ ovom radu simulirana je regeneracija AC-a neizravnim grijanjem primjenom nestacionarnog cilindričnog modela prijenosa topline. Za regeneracijsku cijev vanjskog promjera $108 \mathrm{~mm}$ i debljine stjenke $4 \mathrm{~mm}$ optimalno je grijanje 30 min pri okolnoj temperaturi $550{ }^{\circ} \mathrm{C}$. U tim uvjetima temperatura $417,5{ }^{\circ} \mathrm{C}$ može se postići u središtu cilindrične cijevi čime je dosegnuta temperatura potrebna za regeneraciju AC-a. Eksperimentalne vrijednosti dobivene u laboratoriju bile su u skladu sa simulacijom, čime su dobivene važne referencije za postupno uvećanje pilotnog postrojenja regeneracije AC-a.

\section{Ključne riječi}

Aktivni ugljen, regeneracija, neizravno grijanje, nestacionarni prijenos topline

${ }^{a}$ College of Chemical Engineering, Weifang

Vocational College, Weifang 261 041, Kina

${ }^{b}$ Key Laboratory of Marine Chemistry Theory and Technology, Ministry of Education,

Ocean University of China, Qingdao 266 100,

Kina
Izvorni znanstveni rad Prispjelo 4. svibnja 2016. Prihvaćeno 2. kolovoza 2016. 